\author{
Asian Journal of \\ Medical and Biological Research \\ ISSN 2411-4472 (Print) 2412-5571 (Online) \\ www.ebupress.com/journal/ajmbr
}

\title{
Article \\ Shrimp farming in Southwestern Bangladesh: a case study of economic impacts during COVID-19
}

\author{
Rabeya Akter $^{1 *}$ and Mujibur Rahman Khan ${ }^{2}$ \\ ${ }^{1}$ Department of Fishery Biology \& Genetics, Khulna Agricultural University, Khulna-9100, Bangladesh \\ ${ }^{2}$ Department of Horticulture, Exim Bank Agricultural University Bangladesh, Chapainawabganj-6300, \\ Bangladesh
}

${ }^{*}$ Corresponding author: Rabeya Akter, Department of Fishery Biology \& Genetics, Khulna Agricultural University, Khulna-9100, Bangladesh. Phone: +8801776960777; E-mail: rabeyaakter@kau.edu.bd

Received: 22 August 2021/Accepted: 29 September 2021/ Published: 30 September 2021

\begin{abstract}
Bangladesh is endowed with a long coastline and therefore offers the enormous potential of marine wealth. In the coastal part of Bangladesh, shrimp is one of the most important export-oriented aquacultures due to high-profit return on the same value. Shrimp farming contributes significantly to the livelihoods of rural Bangladeshis in the southwestern region. It is critical to be aware of current culture practices and the measures shrimp farmers take to sustain the trend of exporting shrimp around the world. A random sampling was done of shrimp farmers in the Batiaghata Upazila of Khulna district to learn about the current state of shrimp farming and the challenges they are faced during COVID-19. The recent study reveals that most farmers following semiintensive monoculture practice, application of organic sources in the shrimp pond, selection of PCR tested hatchery-produced Post Larvae (PL) and maintaining good hygiene practice that delivered considerable production of shrimp in this area. But in addition, with these good production farmers also face some difficulties. Some major shrimp diseases were identified in this study including White Feces Disease (WFD), White Spot Syndrome Virus (WSSV), Eosinophilia-Myalgia Syndrome (EMS), Black Gill Disease and some parasite attacks like Zutharium. Lower market price, flood and mortality are other constraints for shrimp farming. The low market price is the major issue for shrimp farmers nowadays around this pandemic situation. As a result, the government, donor agencies, planners, academics, and non-governmental organizations (NGOs) should come forward during the pandemic periods to assist farmers in resolving challenges and ensuring shrimp export revenues of Bangladesh are sustainable.
\end{abstract}

Keywords: coastal area; COVID-19; giant tiger shrimp; productivity, shrimp culture; stocking measures

\section{Introduction}

With the extensive inland, coastal, and marine water resources, Bangladesh, a country blessed with diversified aquatic resources and a land area of $147,570 \mathrm{~km}^{2}$ is regarded one of the top fish-producing countries in the world (Ghose, 2014). The fisheries sector of Bangladesh is one of the most productive and dynamic in the country, and it has played an increasingly important part in the economy in recent decades (Shamsuzzaman $e t$ al., 2017). Bangladesh has made great development in the fisheries industry, contributing significantly to the improvement of food security and socioeconomic status in the dependent population both of which are critically addressed in the United Nations Sustainable Development Goals (SDGs) and in terms of nutritional security, good health and well-being, poverty alleviation, and reduced inequities, fish from capture fisheries and aquaculture help marginalized people preserve their food supply and livelihoods (Sunny et al., 2021a). Coastal aquaculture, which includes shrimp and prawn, finfish, and shrimp cultivation in ghers (ponds/ enclosures), are growing in popularity and farmers who follow Good Aquaculture Practices (GAP) are increasingly interested in adopting environment-friendly shrimp growing systems including cluster shrimp- farmers in a certain area are 
grouped, drawing on common resources like a common water supply channel, and being encouraged to operate collectively rather than individually for the betterment and benefit of everyone. The two main production hubs in Bangladesh are the Khulna, Shatkhira, Bagerhat in the southwest and Chittagong, Cox's Bazar in the southeast for their suitable weather and water quality which are best for shrimp culture. There are 36 species of marine shrimp are available in our country and among them, the target saltwater cultivated species is the giant tiger shrimp (Penaeus monodon Fabricius, 1798) which locally known as Bagda for its higher demand in international markets. Shrimp farming has become one of the most important economic industries in Bangladesh, ranking second only to textiles in terms of exports. (Ahasan, 2012; Rahman and Hossain, 2009). The appropriate climate and environment for organic shrimp culture is identified as a major strength, and the comparative profitability of organic shrimp production over traditional shrimp production is a big opportunity in the southwestern part of Bangladesh (Alauddin and Tisdel, 1998; Pokrant, 2014). The extensive or conventional farming method ( 90 percent of total farms) is one of the key causes of low productivity, whereas developed countries adopted intensive or semi-intensive farming methods (Rahman and Rashid, 2013). A 70\% of shrimp farms in Bangladesh employ traditional or extensive culture techniques, $25 \%$ use semi-intensive culture techniques, and 5\% use intensive culture techniques (Hossain et al., 2013). Organic shrimp production per hectare is 383 pounds, with a benefit-cost ratio of 1.91, indicating that organic shrimp farming is immensely profitable (Dhar et al., 2020). In comparison to their pre-farming socio-economic position, local shrimp farming groups indicated satisfaction with their current income from shrimp farming and it has contributed to an increase in income from $26 \%$ to $36 \%$ for the income ranges of USD 101-150 and > USD 150 which is more profitable than rice farming (Ray et al., 2020). Not only the area of shrimp aquaculture has risen dramatically during the previous three decades, but so has productivity and total shrimp production from 275509 hectares of water bodies was 239798 tons in 2018-19 (DoF, 2019). Total shrimp and prawn production, including capture, has increased from 1.00 lakh MT in 2002-03 to 2.58 lakh MT in 2018-19 and prawn production has been increased over the last 18 years and the total area for shrimp culture estimated as 2.756 Lakh ha (DoF, 2019). Because of the COVID-19 pandemic, shrimp production was halved, the market price was substantially reduced, and the income and livelihood of farmers were severely impacted. Farm incomes declined as national lockdowns restricted access to export markets and mobility inside the country, despite increased production costs. Farmers cut their staff to adjust, yet even with the sale of co-cultured finfish, they still saw significant revenue decreases by 42.8 percent on average (Bashar et al., 2021). Shrimps are more expensive than finfish, and the presence of COVID-19 has inhibited the upper class from visiting markets (Mandal et al., 2021), whilst consumers with lower incomes have been found to prefer finfish to shrimp (Sunny et al., 2021b). As a result, demand for shrimp in local markets has decreased. COVID-19, in general, threatens the livelihoods of thousands of individuals who have no other source of income, pushing more people into poverty and potentially jeopardizing food security in the long run (Mandal et al., 2021). Travel restrictions implemented due to COVID-19 have put the shrimp producers of south-west Bangladesh in financial risk by raising the cost of growing inputs and depressing demand in both the domestic and foreign markets (Bashar et al., 2021). However, this paper demonstrates the development of shrimp production in Bangladesh and how COVID 19 impacts on shrimp production and economies. This study also reveals the aquaculture practices regulated by the farmers at the Batiaghata union.

\section{Materials and Methods}

\subsection{Study area}

The study area was at Batiaghata, a prominent shrimp-farming Upazila in Khulna district, southwestern part of Bangladesh, (Figure 1). This upazila is bordered on the north by the Khulna district headquarters and Rupsa upazila, on the south by the Dakop and Paikgachha upazila. The Batiaghata union of this Upazila was chosen for the study because it has the highest concentration of shrimp farmers and is famous for shrimp production because of the availability of wild post larvae (PL), favorable resources and climatic conditions.

\subsection{Study periods}

The study was conducted for a period from December 2020 to July 2021.

\subsection{Data collection}

Data were collected by interviewing of 30 shrimp farmers in the selected union of Batiaghata Upazilla of Khulna district. Farmers were chosen for questionnaire interview through random sampling and Participatory Rural Appraisal (PRA) tools like Large Group Discussion (LGD), Focus Group Discussion (FGD) and CrossCheck interviews with Key Information (KI). Besides primary information study, secondary data were collected 
from the Department of Fisheries (DOF), Export Promotion Bureau (EPB), relevant journals, thesis, reports and official records.

\subsection{Data analysis}

Collected information obtained from the survey were accumulated, grouped and interpreted according to the objectives and parameters. Some data contained numeric and narrative facts. The collected data were then coded, summarized, processed, tabulated by using simple statistical tools like averages and percentages and analyzed by Microsoft Excel.

\section{Results and Discussion}

\subsection{Status of shrimp farmers}

According to the findings, 70\% of shrimp farmers in Batiaghata Upazila have been active in shrimp farming for more than ten years from 2009-2010 whereas $15.5 \%$ and $14.5 \%$ started shrimp culture in 1989-1990 and 19841985 respectively. That means $70 \%$ of farmers were continuing their shrimp farming for 10-11 years where only $15.5 \%$ had 20 years and the rest were had 24-25 years of shrimp farming experience (Figure 2). According to Chowdhury (2007), about 80 percent of farmers in southern regions began shrimp farming between 2000 and 2004, supporting the current findings. The majority of them which estimated as $60 \%$ made money from shrimp farming and their agricultural properties, while $40 \%$ made money only from shrimp farming. This signifies that the bulk of the people in this area work in the shrimp industry (Figure 3). A similar study was also observed by Matin et al., (2016) which stated that, aside from rice farming, the primary occupation of the locality is shrimp farming. Islam et al., (2016) described in their research that shrimp farming is one of the few viable economic growth choices in coastal districts and it can increase small stakeholder income while also providing relatively well-paid jobs at larger businesses. The majority of the farmers obtained instructions about shrimp culture from Upazila Fisheries Officers, Scientific officers of Bangladesh Fish Research Institute (BFRI), and officials from different NGO's. The rest of them follow successful shrimp farmers who has been involved in this culture for many years. The $80 \%$ cultured shrimp on their land, and those who had been doing so for a long time had six to ten ponds, while $15 \%$ conducted shrimp culture in front of their homes and only had one to two ponds and only $5 \%$ had no land for culture and structured their pond on others land as a lease (Figure 4).

\subsection{Information on shrimp culture pond}

Depending on the size, there are three types of pond in this study that were found and categorized into small (39-44 decimal), medium (49-59 decimal) and large (103 decimal). Islam et al., (2019) noticed that the average pond size was 462 decimals and according to Zafar et al., (2015), the average pond size for shrimp farming was 40 ha (around 98 decimal). About 15\% farmers had small ponds and $75 \%$ had mixed to have both medium and large and the rest $10 \%$ had only large type of ponds (Figure 5). On the converse, the average pond depth was maintained as 4-5 feet depth, but it can be variable depending on the season which was 1-3 feet during the dry season and rise to 3-6 feet in the rainy season, which is similar with the findings of Mamun et al., (2020). Zafar et al., (2015) also said that the average pond size is 1.80 meter (approximately 5 feet) which fully matched with the current study. The majority of the farmers had single ownership whereas only a few had joint ownership.

\subsection{Farming technology}

The majority of the farmers in this field of study practiced semi-intensive monoculture, in which they raised shrimp (Penaeus monodon) and stocked them twice a year. The first stocking began in November and ended at the end of July, while the second stocking took place from July to November. The anticipated study showed that the production rate was higher than the second time stocking and maintained semi-intensive culture system for shrimp production they got the good production rata which was also founded in the research of Dev and Nuruzzaman (2006) who reported that semi-intensive shrimp farming was less detrimental to the environment then intensive systems of shrimp production, and less wasteful of land area than extensive farming.

\subsection{Pre-stocking measures}

\subsubsection{Pond type and embankment structures}

The farmer's ponds were all perennial, and the pond embankments of the majority (55\%) were well-organized (with knowledgeable management of economic benefits can be enhanced and sustained for many years) and complete (with perfect depth, embankment and netting), some (35\%) were well arranged and a few (10\%) were complete (Table 1). Before stocking the post larvae (PL), all of the ponds were thoroughly netted. 
3.4.2. Status of aquatic vegetation and pond drying

There was no aquatic vegetation detected in this study since most of the farmers (90.5\%) carefully maintained their culture areas such that no shrimp died because some animals came to the pond that could bring disease, but only 5\% were with vegetation (Table 1). According to the study of Mamun et al., (2020), all the ponds were dried before stocking the PL.

\subsubsection{Pond preparation}

For better production and to produce quality shrimp pond preparation is done carefully and for this at first the farmers of our research area removed the mud of the pond and then dried the pond. Well established netting was done alongside the entire pond and after that, water was interned into the pond which took a long time varied from 65 to 70 days. The farmers started Pond preparation at November and at the end of the February the PL was released into the pond. When the PL transferred into a market size, harvesting was done and then the pond was again prepared for the second time stocking and this time the pond preparation was done quickly as 10 to 12 days.

\subsubsection{Sources of water supply}

For a productive shrimp culture, a reliable water supply is required. In this area the majority $(90 \%)$ of farmers only used river water, some (5\%) were used rain and tide water and the rest $(5 \%)$ were used only rainwater as the medium for culture (Table 1).

\subsubsection{Water color of the ponds}

The color of the water shows whether or not the pond is productive. In this study area most of the ponds $(73.3 \%)$ were green, some $(23.3 \%)$ were light green and a very few $(3.4 \%)$ were muddy (Table 1$)$. Here the water color varies from green to light green indicated that almost all the ponds were productive. Microorganisms such as phytoplankton, zooplankton, and bacteria, as well as dissolved materials and minerals, clay particles, organic particles, pigments, and suspended colloids, all contribute to the color of water. In the absence of instrumentation, the farmer can use the water color to determine the pond's status. The density of algae in the water dictates its transparency, and the water color is commonly connected with productivity.

\subsubsection{Status of fertilization and fertilizer use}

In this area, the majority (75\%) of farmers followed the semi-intensive culture practice and they used only organic fertilizer where $13.5 \%$ used inorganic fertilizers and the rest $11.5 \%$ used both inorganic and inorganic fertilizers (Table 1). Instead of inorganic fertilizer most of them used rice polish, molasses, yeast powder and in some cases added some minerals etc. Islam et al., (2016) recommended in their studies that for the best productivity and economic profit, promising solutions such as ecological or organic approaches must be considered to reduce nutrient release from shrimp farms and to limit environmental effect by creating a longterm aquatic ecology.

\subsection{Stocking measures}

\subsubsection{Culture species}

For its economic worth and better production rate, Bagda (Penaeus monodon) are the most cultured species in coastal region of Bangladesh. In the current study, most of the farmers (95\%) only farmed Bagda, and they achieved a high output rate by practising good hygiene and the rest $5 \%$ cultured Badga along with some noncommercial species such as prawn, tengra, bele, poa, mullet, coral, tilapia (Table 2).

\subsubsection{Source and quality of Post Larvae (PL)}

In our study area, $85 \%$ of farmers collected the PCR-tested hatchery-produced PL from the Deshbangla hatchery with a 10 to $15 \%$ mortality rate, $10 \%$ from natural sources and $5 \%$ from both hatcheries and natural sources (Table 2). This is quite similar to Mamun et al., (2020), who found that in the southwestern part of Bangladesh, $46.67 \%$ of farmers collected PL from hatcheries, $20 \%$ from natural sources, and $33.33 \%$ from both hatcheries and natural sources wild PL outperformed hatchery-produced PL.

\subsubsection{Stocking density}

For good shrimp production, determining the optimal PL stocking density is incredibly important. In this current study area, $85 \%$ of farmers who used PCR-tested hatchery-produced PL stocked 600-800/decimal whereas 10\% who used natural sources stocked 30-50/decimal and 5\% who used both hatcheries and natural sources stocked 
51-70/decimal on an average. As $85 \%$ of farmers used PCR-tested hatchery-produced PL and their stocking density is high, they stocked two times in a year, so their average stocking in a year estimated as $4,80,000 /$ decimal and the rest $10 \%$ and 5\% annually stocked 3,10,000 - 6,10,000 and > 6,10,000 PL in their farms (Table 2).

\subsubsection{Frequency of PL stocking/ year}

The majority (85\%) of farmers in the Batiaghata union often stocked PL twice a year and the rest $10 \%$ and $5 \%$ stocked ten times/year and nine times/year respectively (Table 2). According to the outcomes of this survey, if the stocking density was larger, the frequency was kept at a lower level which is quite similar to the finding of Mamun et al., (2020), who found that the farmers stocked PL at the rate of 51-90/ decimal and the frequency rate varies from 8 to 10 times a year.

\subsection{Post-stocking measures}

\subsubsection{Feeding}

Almost all farmers rely on artificial feed, which they obtain from reputable companies such as C.P. Shrimp Feed, Avanti Shrimp Feed, and others, which guarantee a protein content of 38-40\%, which is critical for shrimp growth. At the start of the stocking, feeding was done four times a day. The adopted feeding quantity and the feeding schedule (Table 3) mainly for proper utilization of feed, minimal wastage and better growth of shrimp. The initial sampling was done at the age of one month, and after that the feed was administered based on their body weight, with an average estimated body weight feed of 5-6 g (at their 2 percent body weight). This sampling technique was repeated every week until the PL was 120-150 days old, at which point it was ready to be harvested.

\subsubsection{Measurement of water quality parameters}

The majority of the farmers measured water quality parameters and were aware of them to keep the temperature between $28^{\circ} \mathrm{C}$ and $32^{\circ} \mathrm{C}$, the dissolved oxygen level at five ppm, and the $\mathrm{pH}$ between 7.06 and 8.20 (Table 4). Matin et al., (2016), observed that the ideal water parameters for shrimp culture were a temperature range of $250-30^{\circ} \mathrm{C}$ and a $\mathrm{pH}$ range of 7.4-7.9.

\subsubsection{Chemical Application}

The farmers in the current study did not use any chemicals and just used only lime to raise the $\mathrm{pH}$ level of the pond and sometimes they employed Iodine as a disinfectant in some circumstances. Islam and Tabeta (2019) also stated that lime was used to cleanse water and minimize oxygen levels and was preferred over other chemicals because it is less harmful to the environment.

\subsubsection{Use of medicines for disease treatment}

About $90 \%$ of the farmers used ordinary chemicals like $\mathrm{KMnO} 4, \mathrm{CaCO} 3$, Dolomite, and Iodine to cure the disease and the rest $10 \%$ used medicine like aqua clean plus. Shamsuzzaman and Biswas, (2012) stated in their study that the shrimp farmers commonly used chemicals such as oxymax, oxymarine, and oxy plus, as well as antibiotics such as oxysentin $20 \%$, orgamycin $15 \%$, and orgacycline $15 \%$, which are effective against diseases such as dropsy, tail and fin rot, gill rot, and EUS and play an important role in growth promotion and they also found that the most commonly used traditional chemicals in health management included Hme, salt, potassium permanganate, sumithion, melathion,formalin, bleaching powder, malachite green and methyleneblue.

\subsubsection{Exchange of water}

Farmers in the current study usually exchange the pond water in the second time of stocking the PL. Instead of drying their pond this time, they treated the pond water with bleaching powder before returning it to the pond and stocking the PL as a second crop.

\subsubsection{Harvesting of shrimp}

The farmers usually applied the surrounding net (locally known as ber jal), and the pump dried all of the waters. As a result, when the water level began to drop, all of the shrimp congregated in one area. The pond was created with a high embankment and a sloping floor, which was advantageous for harvesting. 


\subsection{Annual production of shrimp}

The average yearly yield of this research area was estimated to be $45 \mathrm{~kg} /$ decimal, indicating that by maintaining a semi-intensive monoculture system of shrimp, the production rate was satisfactory, and the farmers were pleased with the results. Farmers achieved a higher yield in the first stocking than the second stocking, but they minimized their losses by stocking the PL in the nursery pond for 1-1.5 months and then releasing them into the main pond. So, by employing some methods, they were able to achieve a high production rate. If water management and additional feed are appropriately used in conjunction with a high stocking density, intensive culture produces 50 times more than the extensive traditional culture (Primavera, 1993). According to Hosain $e t$ al., (2021) frozen shrimp exports declined from 51,599 MT to 36,167.77 MT between 2010 and 2018, the total value increased from $\$ 340.48$ million to $\$ 416.22$ million, so the shrimp output has gradually increased over the last ten years, and in 2017-2018 it increased by 3.23 percent over 2015-2016 and there is a significant potential for expanding export earnings from shrimp products in the future.

\subsection{Impacts on shrimp production and economies during COVID 19}

Usually, farmers sold their shrimp for 1200-1400 taka per kg (for large sized shrimp), but they only received 700-800 taka per kg due to the pandemic, resulting in a 41-43 percent loss, severely affecting their livelihood. According to Ahmmed et al., (2021), overall shrimp output is marginal, moderate, and large-scale farms in the southwestern coastal part of Bangladesh decreased by 61.35 percent, 77.55 percent, and 72.83 percent, respectively, in 2020 compared to 2019. Sunny et al., (2021a) also stated in their study that the country gained a considerable amount of foreign currency by exporting fish, shrimps, and other fishery products in 2017-18, with a total of BDT 430,994 obtained through the export of 68.94 thousand MT fishing products. As shrimp is the most important exporting item, and because the exporting system is off and somewhat limited as a result of the pandemic, these farmers in this area of research paid special attention to hygiene so that they could get the best production by exporting shrimp and now compensating for heavy losses. Ahmmed et al., (2021) also mentioned in their research that during the COVID-19 pandemic, shrimp production, which is a significant contributor to national GDP, was experiencing significant issues, and nearly all export and import-based businesses were slowing down globally. A worldwide lockdown forced processors to close down, resulting in an oversupply of Shrimps and poor demand, and Shrimp farmers' incomes suffered.

\subsection{Marketing systems of shrimp}

All of the farmers marketed their shrimp to the agent who is the bridge between the farmers and the owner of the processing plant and this is similar to the finding of Dev and Nuruzzaman (2006) who found that farmers in practically all Upazilas in the Khulna area sell all head-on shrimps from gher directly to local markets or shrimp dealers via foria. According to Hassan et al., (2012) Post-harvest handling and marketing channel of shrimp involved six major stakeholder groups viz. farmers, local forias, depot owners, chatal auctioneers, commission agents and factory owners (Figure 6)

\subsection{Problems faced by the shrimp farmers \\ 3.10.1. Shrimp mortality}

Shrimp mortality can occur for a variety of reasons, the most prevalent of which is disease, and numerous important shrimp diseases were detected in this study including White Feces Disease (WFD), White Spot Syndrome Virus (WSSV), Eosinophilia-Myalgia Syndrome (EMS), Black Gill Disease and some parasite attack like Zutharium, which identified as the great problem for them. Shabuj et. al., (2016), found that yellow head viral disease (YHD), white spot syndrome viral (WSSV), vibriosis, fusarium, and protozoan infections were caused by a sudden shift in $\mathrm{pH}$, low dissolved oxygen levels, salinity variations, nutritional deficiencies, and other environmental variables. Another cause of shrimp mortality also identified as aflatoxin (B1, B2, G1, G2), a fungus-derived agricultural pollutant with acute and chronic effects on human and animal health, is discovered in a variety of crops such as maize, wheat, soybeans, and other grains that are used as raw materials in the production of fish and shrimp feed (Parvez et. al., 2020).

\subsubsection{Low market price}

The most common issue was low market pricing, which has become a source of concern for shrimp farmers, especially in the wake of the pandemic. Aside from that, Because of inconsistencies in the supply chain, shrimp prices in the local and worldwide markets fluctuate dramatically (Nupur, 2010). Due to the unpredictable price, shrimp growers may not always get the best price. Drought, lack of transportation, market distance, inadequate 
road infrastructure, intimidation by professional fish dealers, and shrimp theft are also responsible for low market price of shrimp (Mamun et al., 2020).

Table 1. Pre-stocking condition of shrimp farming in Southwestern part of Bangladesh

\begin{tabular}{lll}
\hline Characteristics & Categories & $\begin{array}{l}\text { Percentages of farmers } \\
\text { in the study area (\%) }\end{array}$ \\
\hline \multirow{3}{*}{ Embankment Structures } & Complete & $10 \%$ \\
& Well-arranged & $35 \%$ \\
Status of aquatic Vegetation & Complete + Well arranged & $55 \%$ \\
\hline \multirow{2}{*}{ Source of water Supply } & With vegetation & $90.5 \%$ \\
& Without vegetation & $5 \%$ \\
\hline \multirow{2}{*}{ Water colour of the ponds } & River water & $90 \%$ \\
& Rainwater + Tide water & $5 \%$ \\
& Rainwater & $5 \%$ \\
\hline \multirow{2}{*}{ Fertilization } & Green & $73.3 \%$ \\
& Light Green & $23.3 \%$ \\
& Muddy & $3.4 \%$ \\
\hline
\end{tabular}

Table 2. Stocking condition of shrimp farming in Southwestern part of Bangladesh

\begin{tabular}{lll}
\hline Characteristics & Categories & $\begin{array}{l}\text { Percentages of farmer's in } \\
\text { the study area (\%) }\end{array}$ \\
\hline \multirow{2}{*}{ Culture species } & Commercial & $95 \%$ \\
& Commercial + non-commercial & $5 \%$ \\
Source of Post Larvae (PL) & Hatchery produced & $85 \%$ \\
& Natural source & $10 \%$ \\
& Both (natural + hatchery produced) & $5 \%$ \\
\hline \multirow{2}{*}{ Stocking density (PL / decimal) } & $600-800 /$ decimal & $85 \%$ \\
& $30-50 /$ decimal & $10 \%$ \\
& $51-70 /$ decimal & $5 \%$ \\
\hline & $4,80,000 /$ decimal & $85 \%$ \\
Stocking density (PL / year) & $3,10,000-6,10,000 /$ decimal & $10 \%$ \\
& $>6,10,000 /$ decimal & $5 \%$ \\
\hline \multirow{2}{*}{ Frequency of PL (stocking /year) } & 2 times & $85 \%$ \\
& 10 times & $10 \%$ \\
\hline
\end{tabular}

Table 3. Feeding schedule for Tiger shrimp (Initial 30 Days)

\begin{tabular}{lll}
\hline Days of culture & Feed increase/Day/ 1000 PL & Feed /Day/1000 PL \\
\hline 1 & - & $20 \mathrm{~g}$ \\
$2-10$ & $3 \mathrm{~g}$ & $23 \mathrm{~g}-25 \mathrm{~g}$ \\
$11-20$ & $4 \mathrm{~g}$ & $27 \mathrm{~g}-30 \mathrm{~g}$ \\
$21-30$ & $5 \mathrm{~g}$ & $32 \mathrm{~g}-35 \mathrm{~g}$ \\
\hline
\end{tabular}

Table 4. Suitable water quality parameters for shrimp culture

\begin{tabular}{ll}
\hline Parameters & Estimated value \\
\hline Temperature & $28-32^{0} \mathrm{C}$ \\
Dissolve oxygen & $5 \mathrm{ppm}$ \\
$\mathrm{P}^{\mathrm{H}}$ & $7.06-8.20$ \\
\hline
\end{tabular}




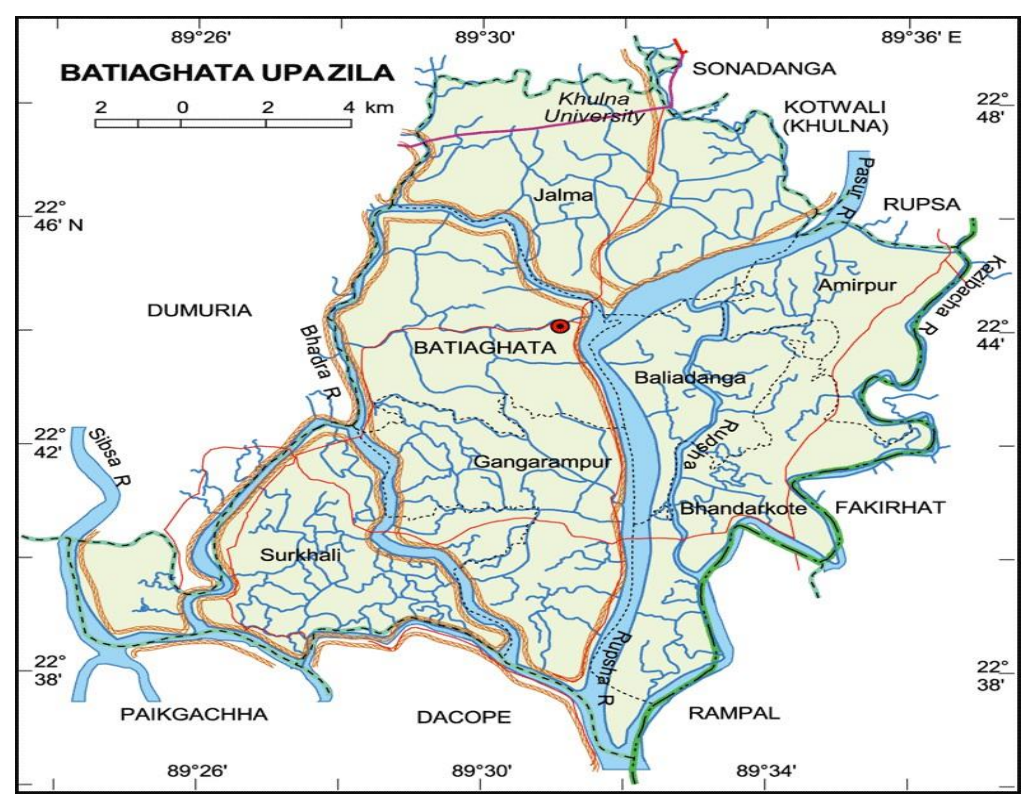

Figure 1. Schematic diagram of the study area, Batiaghata Upazila (Source: Banglapedia)

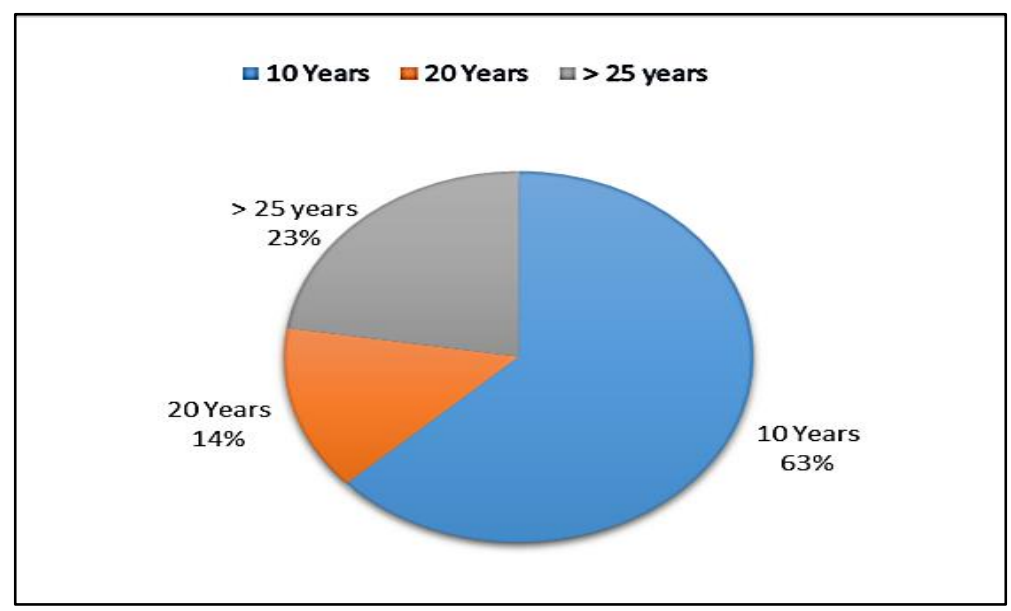

Figure 2. The number of years the farmers have been involved in shrimp farming (in percentage).

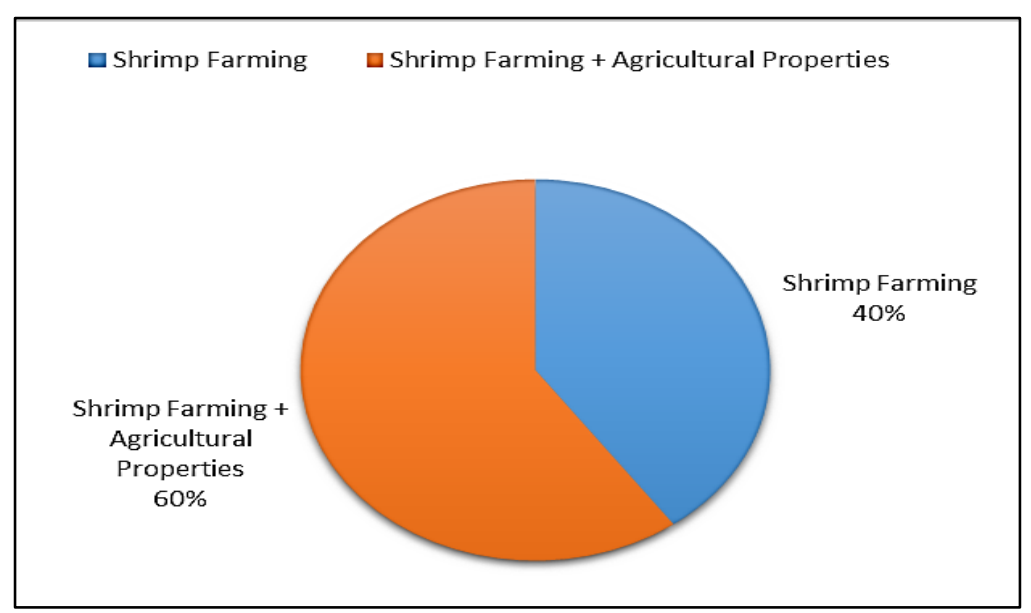

Figure 3. The livelihood pattern of the shrimp farmers in the southwestern region (in percentage). 


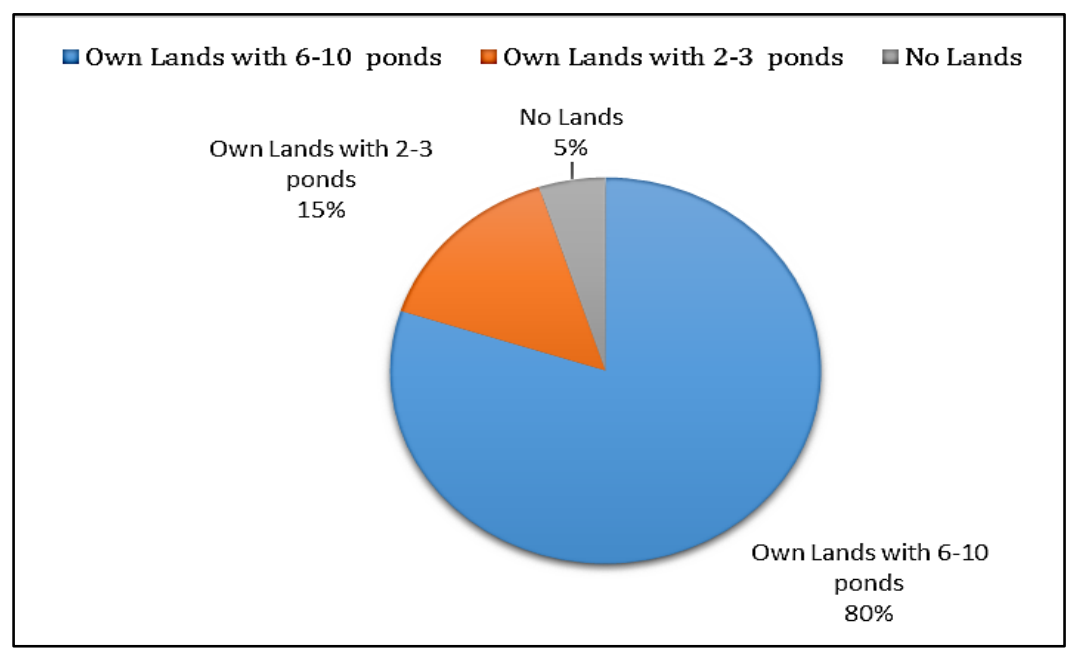

Figure 4. The numbers of pond in which the farmers culture the shrimp (in percentage).

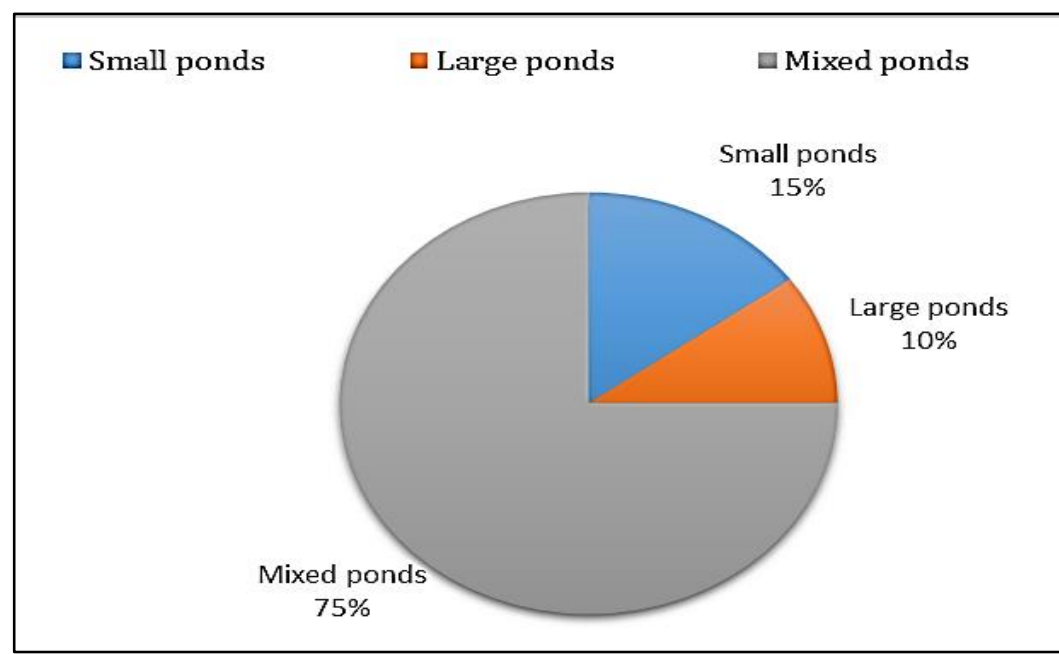

Figure 5. The types of pond the farmers have (in percentage).

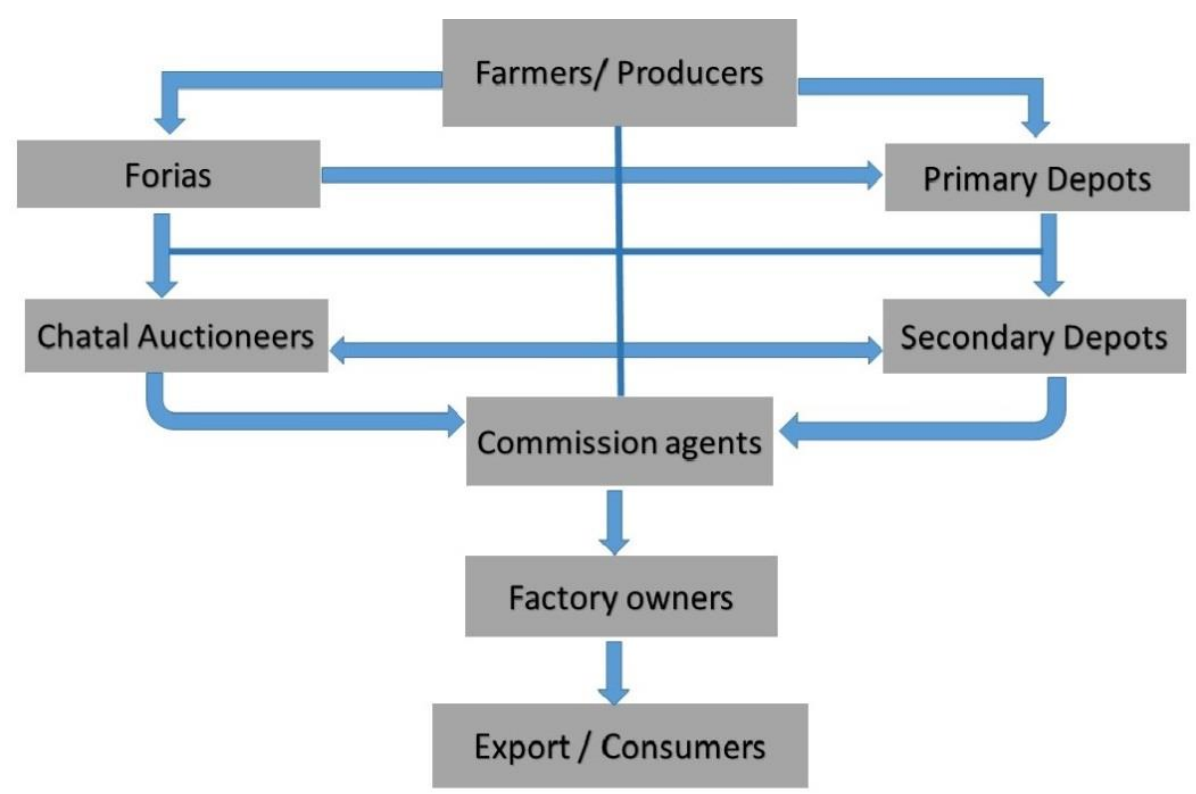

Figure 6. Shrimp marketing channel in Bangladesh, adapted from Hassan et al., (2012) 


\section{Conclusions}

Shrimp aquaculture provides significant environmental and social benefits. The shrimp sector has been highlighted as a viable alternative to fishery production providing various job opportunities for rural residents. The purpose of this study was to determine the state of shrimp culture and the financial profit gained by shrimp monoculture farming from a variety of perspectives and by employing these methods, they were able to make a fair profit. Like most sectors, the aquaculture and fisheries sector economy, particularly in developing countries such as Bangladesh, is believed to have been severely impacted by this unique coronavirus (COVID-19) pandemic, and to overcome the adverse effects of COVID-19, the aquaculture and fisheries economy requires immediate recovery plans to compensate for the significant losses.

\section{Conflicts of interest}

None to declare.

\section{Authors' contribution}

Conceptualization: Rabeya Akter; methods: Rabeya Akter and Mujibur Rahman Khan; data collection: Rabeya Akter and Mujibur Rahman Khan; statistics and presentation: Rabeya Akter and Mujibur Rahman Khan; writing, original draft preparation: Rabeya Akter; writing, review and editing: Rabeya Akter and Mujibur Rahman Khan. All authors have read and agreed to the published version of the manuscript.

\section{References}

Ahasan DA, 2012. Bangladesh's winning maritime boundary, development, conservation and management of fish resources, National Fish Week 2012 Compendum (in Bengali), Narinda, Dhaka. Department of Fisheries, Ministry of Fisheries and Livestock, GoB., 23-25.

Ahmmed S, MR Washim, ASA Rubel, and ML Islam, 2021. Outbreak of COVID-19: Impact on socioeconomic condition of shrimp farmers in South-West coastal Bangladesh. Asian J. Fish. Aqua. Res., 12: 2029.

Alauddin M and Tisdel C, 1998. Bangladesh's shrimp industry and sustainable development: resource use conflict and development. Asian Fish Sci., 11: 97-110.

Bashar A, RD Heal, NA Hasan, and MM Haque, 2021. Effect of COVID-19 on shrimp aquaculture in Bangladesh. SSRN Electron. J., 31: 7896.

Chowdhury AR, 2007. Farming Practices and Marketing of Shrimp at Farmers Level in Bagerhat District. MS Thesis, Department of Aquaculture, Bangladesh Agricultural University, Mymensingh, pp. 33.

Dev BK and M Nuruzzaman, 2006. Present status of shrimp at the stage of production and marketing: A study in Khulna district of Bangladesh. Dhaka: Department of Fisheries, Ministry of Fisheries and Livestock, 9.

Dhar AR, Uddin MT and Roy MK, 2020. Assessment of organic shrimp farming sustainability from economic and environmental viewpoints in Bangladesh. Environ. Res., 180: 108879.

DoF, 2019. Yearbook of fisheries statistics of Bangladesh, 2018-19. Fisheries Resources Survey System (FRSS), Department of Fisheries, Ministry of Fisheries and Livestock, Dhaka, Bangladesh, 36:135

Ghose B, 2014. Fisheries and aquaculture in Bangladesh: Challenges and opportunities. Annals of Aquac. and Res., 1:1-5.

Hassan MN, MM Rahman, MM Hossain, AA Nowsad and MB Hossain, 2012. Post-harvest handling and marketing of shrimp and prawn in south-western region of Bangladesh. World J. Fish Mar. Sci., 4:651-656.

Hosain MA, K Ullah, MA Al Sayam, K Mohiuddin and E Rahman, 2021. Present Status and Future Direction of Bangladeshi Shrimp Resources. Fish. and Aquac. J., 12:1c.

Hossain MS, MJ Uddin and ANM Fakhruddin, 2013. Impacts of shrimp farming on the coastal environment of Bangladesh and approach for management. Rev. Env. Sci. Biotech., 12:313-332.

Islam MA, MA Akber, M Ahmed, MM Rahman and MR Rahman, 2019. Climate change adaptations of shrimp farmers: a case study from southwest coastal Bangladesh. Clim. Dev., 11: 1-10.

Islam MR and S Tabeta, 2019. Shrimp vs prawn-rice farming in Bangladesh: A comparative impacts study on local environments and livelihoods. Ocean. Coast. Manag., 168:167-176.

Islam SD and MA Bhuiyan, 2016. Impact scenarios of shrimp farming in coastal region of Bangladesh: an approach of an ecological model for sustainable management. Aquac. Int., 24:1163-90.

Mamun MA, MG Ara, KN Azad, J Fatema, ZF Ahmed and MK Fatema, 2020. Present Status of Shrimp Farming in Satkhira, a Southwestern District of Bangladesh. Res. Agri. Live. Fish, 7:311-20. 
Mandal SC, P Boidya, MI Haque, A Hossain, Z Shams and AA Mamun, 2021. The impact of the COVID-19 pandemic on fish consumption and household food security in Dhaka city. Bangladesh Glob. Food Sec., 12:100526.

Matin MA, S Chakraborty, M Al Amin and A Ghosh, 2016. An assessment of shrimp aquaculture in selected coastal areas of Bangladesh. J. NOAMI, 33: 103-116.

Nupur JM, 2010. Problems and Prospects of Shrimp Farming in Bangladesh, AIUB Bus. Econ. Working Paper Series, 2010-05.

Parvez MA, MB Alam and MM Mia, 2020. Confirmation of aflatoxin in fish and shrimp by LC/MS-MS (ZEVO TQD). Asian Australas. J. Food Saf. Secur.,4:14-21.

Pokrant B, 2014. Brackish water shrimp farming and the growth of aquatic monocultures in coastal Bangladesh. In Historical perspectives of fisheries exploitation in the Indo-Pacific. Springer, Dordrecht, 107-132.

Primavera JH, 1993. A critical review of shrimp pond culture in the Philippines. Rev. Fish Sci., 1:151-201.

Rahman MC and MHA Rashid, 2013. A case study on the present status and potentiality of shrimp farming in Bangladesh. Asia-Pacific J. Rur. Dev., 23: 97-110.

Rahman MM and MM Hossain, 2009. Production and export of shrimp of Bangladesh: Problems and prospects. Prog. Agri., 20:163-171.

Ray S, P Mondal, AK Paul, S Iqbal, U Atique, MS Islam, S Mahboob, KA Al-Ghanim, F Al-Misned and S Begum, 2021. Role of shrimp farming in socio-economic elevation and professional satisfaction in coastal communities of Southern Bangladesh. Aquac. Rep., 20:100708.

Shabuj MA, T Bairagi, A Al Asif, O Faruq, MR Bari and MS Neowajh, 2016. Shrimp disease investigation and culture strategies in Bagerhat district, Bangladesh. Bangladesh. Asian J. Med. Biol. Res., 1:545-552.

Shamsuzzaman MM and TK Biswas, 2012. Aqua chemicals in shrimp farm: A study from south-west coast of Bangladesh. Egypt. J. Aquatic Res., 38:275-85.

Shamsuzzaman MM, MM Islam, NJ Tania, MA Al-Mamun, PP Barman and X Xu, 2017. Fisheries resources of Bangladesh: Present status and future direction. Aquac. and Fish., 2:145-56.

Sunny AR, MH Mithun, SH Prodhan, M Ashrafuzzaman, SM Rahman, MM Billah, M Hussain, KJ Ahmed, SA Sazzad, MT Alam and A Rashid, 2021a. Fisheries in the context of attaining Sustainable Development Goals (SDGs) in Bangladesh: COVID-19 impacts and future prospects. Sustainability,13:9912.

Sunny AR, SA Sazzad, SH Prodhan, M Ashrafuzzaman, GC Datta, AK Sarker, M Rahman and MH Mithun, 2021b. Assessing impacts of COVID-19 on aquatic food system and small-scale fisheries in Bangladesh. Mar. pol., 126:104422.

Zafar MA, MM Haque, MS Aziz and MM Alam, 2015. Study on water and soil quality parameters of shrimp and prawn farming in the southwest region of Bangladesh. J. Bangladesh Agric. Univ., 13:153-60. 